\title{
Work-related medical rehabilitation in patients with mental disorders: the protocol of a randomized controlled trial (WMR-P, DRKS00023175)
}

\author{
Miriam Markus ${ }^{1 *}$, Nina Gabriel ${ }^{2}$, Markus Bassler ${ }^{2}$ and Matthias Bethge ${ }^{1}$
}

\begin{abstract}
Background: Various rehabilitation services and return-to-work programs have been developed in order to reduce sickness absence and increase sustainable return-to-work. To ensure that people with a high risk of not returning to work can participate in working life, the model of work-related medical rehabilitation was developed in Germany. The efficacy of these programs in patients with mental disorders has been tested in only a few trials with very specific intervention approaches. To date, there is no clear evidence of the effectiveness of work-related medical rehabilitation implemented in real-care practice.

Methods/design: Our randomized controlled trial will be conducted in six rehabilitation centers across Germany. Within 15 months, 1800 patients with mental disorders (300 per rehabilitation center) will be recruited and assigned one-to-one either to a work-related medical rehabilitation program or to a conventional psychosomatic rehabilitation program. Participants will be aged 18-60 years. The control group will receive a conventional psychosomatic rehabilitation program without additional work-related components. The intervention group will receive a work-related medical rehabilitation program that contains at least $11 \mathrm{~h}$ of work-related treatment modules. Follow-up data will be assessed at the end of the rehabilitation and 3 and 12 months after completing the rehabilitation program. The primary outcome is a stable return to work. Secondary outcomes cover several dimensions of health, functioning and coping strategies. Focus groups and individual interviews supplement our study with qualitative data.
\end{abstract}

Discussion: This study will determine the relative effectiveness of a complex and newly implemented work-related rehabilitation strategy for patients with mental disorders.

Trial registration: German Clinical Trials Register (DRKS00023175, September 29 2020).

Keywords: Work-related medical rehabilitation, Effectiveness, Work ability, Return to work, Mental disorders

\footnotetext{
*Correspondence: miriam.markus@uksh.de

'Institute of Social Medicine and Epidemiology, University of Lübeck,

Ratzeburger Allee 160, 23562 Lübeck, Germany

Full list of author information is available at the end of the article
}

(c) The Author(s). 2021 Open Access This article is licensed under a Creative Commons Attribution 4.0 International License, which permits use, sharing, adaptation, distribution and reproduction in any medium or format, as long as you give appropriate credit to the original author(s) and the source, provide a link to the Creative Commons licence, and indicate if changes were made. The images or other third party material in this article are included in the article's Creative Commons licence, unless indicated otherwise in a credit line to the material. If material is not included in the article's Creative Commons licence and your intended use is not permitted by statutory regulation or exceeds the permitted use, you will need to obtain permission directly from the copyright holder. To view a copy of this licence, visit http://creativecommons.org/licenses/by/4.0/ The Creative Commons Public Domain Dedication waiver (http://creativecommons.org/publicdomain/zero/1.0/) applies to the data made available in this article, unless otherwise stated in a credit line to the data. 


\section{Background}

The 12-month prevalence of mental disorders in the German general population is about $30 \%$. Contrary to public perception, this prevalence rate has been remarkably stable since the 1970 s $[1,2]$. However, the consequences of illness are becoming more visible: sickness absence [3, 4], health-related early retirement [5] and recognized severe disabilities [6] due to mental disorders have increased significantly in recent years. A study in general practitioners' practices has shown that people with mental disorders have twice as many days of sickness absence as people with chronic somatic illnesses [7].

In many countries, rehabilitation services are available to support patients with chronic diseases in order to enable work participation [8]. In Germany, roughly one-sixth of inpatient rehabilitation programs for working-age people are provided to those with mental disorders (total: 16.7\%; men: 12.7\%; women: 20.7\%) [9]. Depression, adjustment disorders, somatoform disorders and anxiety disorders are the most frequent disorders treated [10].

Due to the adverse consequences of mental illness for work participation, researchers have increasingly used work participation outcomes to appraise the effects of rehabilitation programs in recent years. In a randomized controlled trial, Hillert and colleagues have investigated the effects of a work-related medical rehabilitation (WMR) approach in a sample of patients with long-term sickness absence and unemployed patients. Participants in the intervention group were exposed to real work environments by completing part-time internships outside the rehabilitation center over a period of 4 weeks. This work exposure was accompanied by behavioral therapy in the rehabilitation department. One year after the rehabilitation program, participants in the intervention group returned to work significantly more often and reported more positive job-related attitudes [11]. A study by Beutel and colleagues examined the effects on work participation outcomes of a similar program but followed a psychodynamic instead of a behavioral approach. These authors reported shorter sickness absences and more positive attitudes towards work for the intervention group [12]. Nieuwenhuijsen et al. [13] conducted a Cochrane Review to investigate whether occupational interventions in depressed patients, in addition to clinical interventions, promote return to work. They analyzed data from three randomized controlled trials with 251 patients. In these trials, concrete action plans for work problems were developed, but the scope and focus of the interventions varied. In two of the three studies, the employer or the company medical officer was contacted. The duration of sickness absence during the follow-up period was reduced by almost half a standard deviation compared with the control group (standardized mean difference: -0.40 ; $95 \%$ confidence interval: -0.66 to $0.14)$. The quality of the evidence was downgraded from high to moderate due to the low number of patients included in the meta-analysis. In summary, the national and international studies show that additional work components that are closely linked to conventional psychosomatic treatment can achieve more favorable work participation outcomes.

Rehabilitative services provided by the German Pension Insurance aim at work participation and the avoidance of disability pensions. The increasingly stronger orientation towards these goals is reflected in the dissemination of WMR programs. For the implementation of such programs, pension insurances have developed joint recommendations concerning target group, content and scope. These recommendations are summarized in the WMR guidelines [14-17]. WMR programs regularly comprise a diagnostic assessment that compares job demands and patients' work capacity and offers therapeutic interventions such as work hardening and work-related functional capacity training, work-related psychosocial groups and intensified social counseling (see also the Methods section) $[15,18-20]$. The aim of WMR is to improve the work participation of persons at high risk of not returning to work by taking greater account of individual work demands and the required skills. Possible indicators of a high risk of not returning to work are, for example, long-term or repeated sick leave and an unfavorable subjective poor return-to-work expectation. Representative administrative data indicated that $57 \%$ of the patients with mental disorders undergoing rehabilitation in 2013 may have an increased risk of not returning to work due to long-term sickness absence before rehabilitation, unemployment at the time of applying for rehabilitation or reduced work capacity in the last job as determined by a socio-medical evaluation [14, 16]. Up to now, the evidence regarding the efficacy of WMR in mental disorders has been based on only two randomized controlled trials, and these trials have tested a very specific approach (work exposure and accompanying psychotherapeutic groups). There is no clear evidence of the effectiveness of the WMR implemented in real-care practice based on the WMR guidelines.

\section{Objectives}

We hypothesize that WMR improves stable return to work 12 months after rehabilitation (primary outcome) compared with conventional psychosomatic rehabilitation (CPR). Moreover, we expect more favorable secondary outcomes in patients treated with WMR. 


\section{Trial design}

The study is a randomized controlled trial with two parallel groups. Participants are randomly assigned to a WMR or CPR group in a one-to-one ratio. Focus groups and individual interviews supplement our study with qualitative data.

\section{Methods}

\section{Study setting}

Participants will receive either a WMR or CPR program in one of six rehabilitation centers located in Germany (Rehazentrum Oberharz in Clausthal-Zellerfeld, RehaZentrum Seehof in Teltow, Fachklinik Aukrug, Klinik am Hainberg in Bad Hersfeld, Celenus Parkklinik in Bad Bergzabern and MediClin Bliestal Kliniken in Blieskastel). The rehabilitation programs will be provided as inpatient programs. Participation was approved either by the Federal German Pension Insurance or a regional pension insurance agency. In both programs, interventions will be performed by rehabilitation physicians, psychologists, physiotherapists, sports therapists, social workers, occupational therapists and other health professionals.

The duration of the rehabilitation program is initially determined by the pension insurance agency (usually about 5 weeks). The rehabilitation center and the patient can agree on an extension of the program. By request, the patient may stop the rehabilitation program ahead of schedule.

\section{Eligibility criteria}

Patients are aged 18-60 years and have chronic mental disorders. Only patients with a need for WMR (i.e. with severe restrictions in work ability and a higher risk of not returning to work) will be included in the study. Patients have requested rehabilitation due to mental disorders interfering with work ability. Need for rehabilitation was acknowledged by a registered doctor and approved by the pension insurance agency. After approval, the pension agencies assign patients to the participating rehabilitation centers. The need for WMR is identified in the participating rehabilitation center by the SIMBO-C, a standardized screening instrument [21-24]. Patients are eligible if they have a risk score of at least 27 out of 100 points.

\section{Treatment}

\section{Control}

Participants of the control group will receive a CPR program according to current treatment standards and guidelines for the rehabilitation of mental disorders. CPR programs last approximately 5 weeks. The duration of daily therapy amounts to 3 or $4 \mathrm{~h}$. Following a multimodal approach, CPR programs include psychotherapy, psychoeducation, relaxation training, sports and exercise therapy, health education, expressive arts therapy, occupational therapy, social counseling and initiation of follow-up care. CPR programs address past and present mental health problems and aim to prevent a relapse. Patients are supported in recognizing and changing dysfunctional patterns of behavior and relationships and in developing behavioral alternatives. In contrast to WMR programs, they do not integrate an explicit focus on work, work ability and return to work in the diagnostics and therapy. Rehabilitation follows the recommendations of the guidelines for inpatient rehabilitation centers concerning the medical rehabilitation of adults with psychosomatic and mental disorders $[25,26]$.

\section{Intervention}

Participants of the intervention group will receive a WMR program according to the guidelines for WMR $[15,27]$ as well as the current treatment standards and guidelines for the rehabilitation of mental disorders. WMR programs contain at least $11 \mathrm{~h}$ of work-related treatment modules [17]. As with the CPR programs, WMR programs follow a multimodal approach that comprises psychotherapy, psychoeducation, relaxation training, sports and exercise therapy, health education, expressive arts therapy, occupational therapy, social counseling and initiation of follow-up care. However, WMR programs more explicitly focus on work, work ability and return to work by including additional workrelated diagnostics as well as work-related functional capacity training, work-related psychosocial groups and intensified social counseling. Table 1 describes the core modules in line with the TIDieR checklist [33].

\section{Outcomes and other measures}

This study will assess one primary outcome as well as secondary outcomes and moderator variables. Outcomes and other measures will be assessed with patient questionnaires or extracted from the rehabilitation discharge letters. A complete list of all measured constructs, measurement points and expected scaling is shown in Table 1.

\section{Primary outcome}

The primary outcome of this study is stable return to work 12 months after rehabilitation. Return to work will also be assessed at the three-month follow-up. Stable return to work has been defined in accordance with Kuijer and colleagues [34] as a minimum of 4 weeks of employment without sick leave at follow-up.

\section{Secondary outcomes}

Secondary outcomes cover several dimensions of health, functioning and coping strategies (see below) and will be 


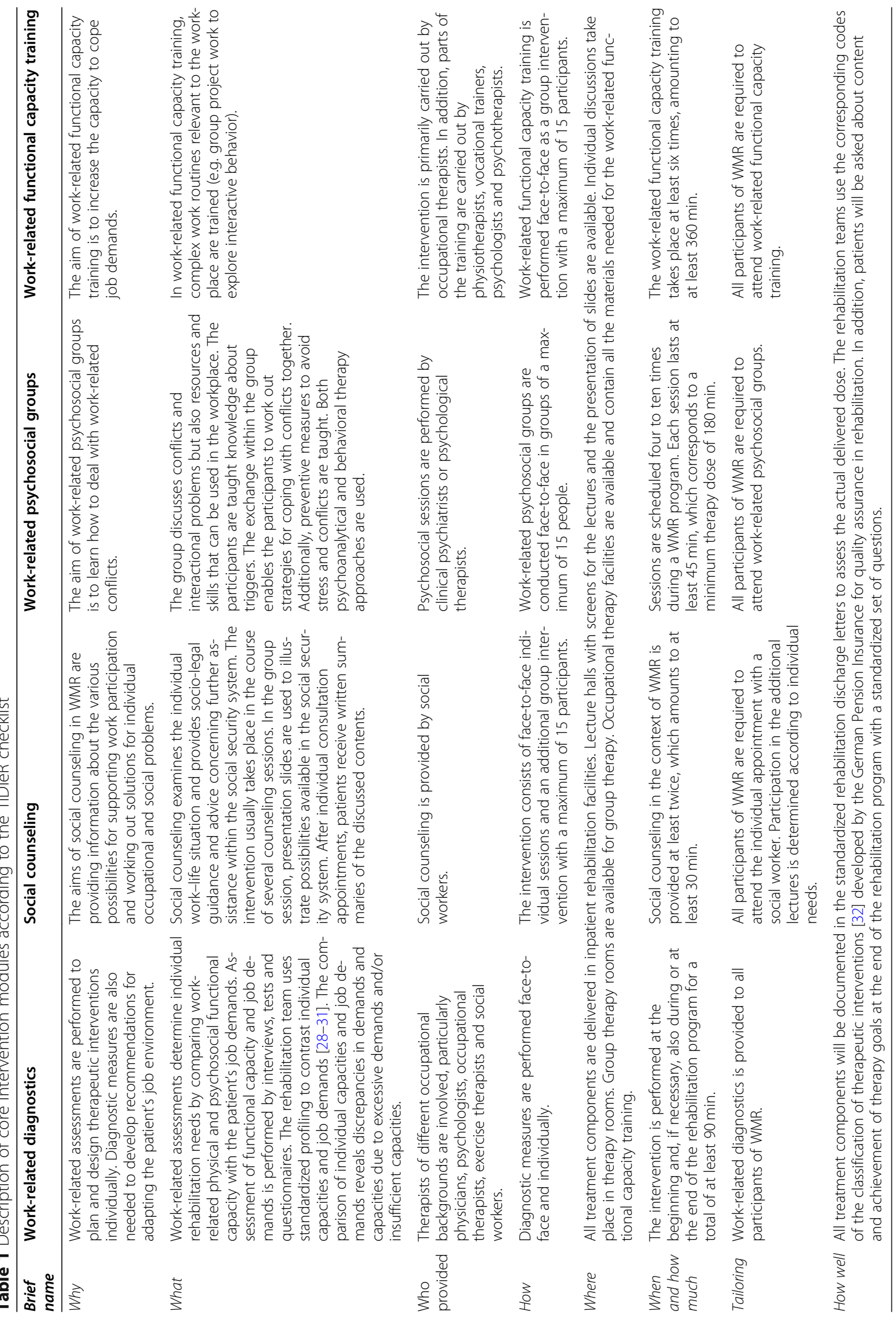


measured at all four measurement points. At the first follow-up after completing the rehabilitation program, participants will also appraise how the rehabilitation programs dealt with work-related issues and how satisfied they were with the treatment.

\section{Employment}

To cover participation in working life, the employment status (employed vs. unemployed) is noted. We record the professional position and economic sector. Moreover, we will assess if patients are on sick leave and how long they have been on sick leave. To assess the duration of sick leave, participants will be asked to report the number of weeks they have been off work for health reasons since discharge from the rehabilitation center. At baseline, this question is related to the last 12 months.

\section{Self-reported work ability}

Work ability will be assessed by the Work Ability Score (WAS), which is the first item of the Work Ability Index (WAI) [35] and compares current work ability with the lifetime best. The 11-point scale ranges from 0 (complete incapacity to work) to 10 (lifetime's best work ability). The WAS is highly correlated with the overall WAI score [36].

\section{Health-related quality of life}

The 36-Item Short-Form Health Survey (SF-36) will be used to assess the health-related quality of life [37]. The SF-36 comprises eight subscales: physical functioning, physical role function, physical pain, general health perception, vitality, social functioning, emotional role function and psychological well-being. Each score lies in the range $0-100$ points, with higher values indicating better health-related quality of life.

\section{Psychosocial health}

Psychosocial health will be measured by three modules of the German survey "HEALTH-49" (Hamburger Module zur Erfassung allgemeiner Aspekte psychosozialer Gesundheit für die therapeutische Praxis) [38]. The first module consists of three scales with a total of 18 items and assesses psychological and somatoform symptoms. The three subscales are somatoform disorders (7 items), depression (6 items) and phobic anxieties (5 items). Patients will be asked if they suffered from different symptoms such as back pain, headache or hopelessness in the last 2 weeks. All items were five-point graded $(0=$ not, $1=$ little, 2 =medium, 3 =quite, $4=$ much). The second module covers interactional difficulties. Patients will be asked if they had difficulties in interactional situations (e.g. "showing feelings to other people") in the last 2 weeks. The module consists of one scale with seven items that were also five-point graded $(0=$ not, $1=$ little,
$2=$ medium, 3 =quite, $4=$ much). The third module assesses self-efficacy. With five items patients will be asked to state to what extent they feel able to do tasks, deal with strains or do things that are important to them despite their complaints. All items of the five-point scale from 0 (completely disagree) to 4 (completely agree) will be reversed afterwards. In each case the total score is the unweighted mean of all items, with higher values indicating higher impairments.

\section{Job-related anxieties}

A short 13-item form of the Job Anxiety Scale [39, 40] will be used to assess panic and fear regarding the workplace. Patients will be asked how much they agree with a set of situations, thoughts and feelings that can be experienced in connection with the workplace, e.g. "When I think about my workplace, I notice how everything inside me is tensed". Responses range from 0 (completely disagree) to 4 (completely agree). All item scores will be averaged.

\section{Regeneration and resistance beliefs}

In order to assess attitudes and beliefs about coping with stressful events, a 20-item German questionnaire (Resistenzorientierung-Regenerationsorientierungs-

Skala, ReRe) will be used [41]. Ten items each are used to assess the extent to which patients prefer coping strategies that focus on either recovery or endurance. Responses range from 1 (completely disagree) to 5 (completely agree). Individual items will be averaged to gain a regeneration score and an endurance score. Higher scores indicate higher regeneration or endurance.

\section{Received dose of work-related treatment components}

To assess the fidelity of our intervention according to the patients treated, we will employ a slightly modified version of a previously used set of items from a study that investigated the nationwide implementation of the WMR guidelines in patients with musculoskeletal disorders [42]. Participants report on 12 binary items as to whether they received WMR content in their rehabilitation program. Scores are aggregated to a total score of $0-12$ points. This score reflects the content of the workrelated components. Additionally, six items assess the perceived consistency of the work-related approach (e.g. the experience of a coherent return-to-work strategy). These items are five-point graded and scores are summed to a total score of $0-24$ points. Finally, the achievement of work-related goals will be assessed by eight items that are also five-point graded and scores are aggregated to a total score of $0-32$ points. 


\section{Treatment satisfaction}

Treatment satisfaction will be assessed using the German version of the Client Satisfaction Questionnaire (CSQ-8) [43]. This questionnaire comprises eight items designed to assess various aspects of the patient's satisfaction with treatment. Responses are four-point graded and the overall score lies in the range 8-32 points.

\section{Other measures}

Additional measures will be assessed as potential effect modifiers and to conduct a health economic analysis.

\section{Delivered dose of work-related components}

Therapeutic interventions will be extracted from the standardized rehabilitation discharge letters [44]. The documentation for the therapeutic interventions will indicate adherence to the WMR guidelines. The delivered intervention dose is also a potential effect modifier.

\section{Socio-medical assessment of capacity}

Capacity for the most recent occupational activity and the general labor market, as well as recommendations for subsequent benefits, is assessed by the rehabilitation center. We take the information from the rehabilitation discharge letters [44].

\section{Socio-demographic data}

We will ask participants for socio-demographic data (age, gender, native language, educational level, partnership and children).

\section{Use of medical and non-medical health care services}

For our health economic evaluation we use the German Questionnaire for Health-Related Resource Use in an Elderly Population (Fragebogen zur Inanspruchnahme medizinischer und nicht-medizinischer Versorgungsleistungen im Alter, FIMA) [45]. We will ask about the type of health insurance, the medication taken in the last 7 days, outpatient visits to the doctor and therapeutic services used in the last 3 months, rehabilitation measures, outpatient operations or stays in day clinics and inpatient treatment in the last 12 months. We will evaluate the answers with calculated unit costs [46]. See Table 2 for measures, assessment, expected scaling and maesurement occasions.

\section{Participant timeline}

Participants fill in the baseline questionnaire at the beginning of rehabilitation. At the end of rehabilitation the participants fill in the first follow-up questionnaire at the rehabilitation center. At the 3- and 12-month follow-ups, participants who completed the baseline questionnaire will receive follow-up questionnaires from the University of Lübeck. Focus groups with some of the participants will be conducted during the intervention as well as three and 12 months after rehabilitation (see Table 3 for a full schedule of enrolment, interventions and assessments).

\section{Sample size estimation}

In order to ensure a $20 \%$ increase in the proportion of rehabilitants with stable return to work per rehabilitation center (CPR: $40 \%$; WMR: 60\%; power: $80 \%$; level of significance: $5 \%$ ), an analysis sample of 194 persons (i.e. 97 persons per intervention arm) is necessary. Although we will use multiple imputations to perform an intention-to-treat analysis, we increase the sample size to compensate for the potential loss of participants during our follow-up assessments. This ensures sufficient power even if only complete cases are analyzed. Assuming a response rate of $65 \%$ after 1 year, we will recruit 300 patients per rehabilitation center. In a total sample of 1800 patients, a minimal difference of seven points can be detected. In a total sample of 1164 patients (response rate of $65 \%$ ), a minimal difference of eight points can be detected (Fig. 1).

Of the 1800 persons recruited, eight patients from each of the intervention and control groups are supposed to take part in interviews for a panel study. The patients should be in the third week of their rehabilitation program. The second and third follow-up interviews will be conducted with three persons from these focus groups. The focus groups with the team members are planned with five persons per rehabilitation center. The number of participants in the focus groups with the team leaders will depend on the number of teams per rehabilitation center.

\section{Recruitment}

The rehabilitation centers check all newly arrived rehabilitation patients with mental disorders between the ages of 18 and 60 years to see whether they have an increased risk of not returning to work. This will be detected using the SIMBO-C [24]. In the case of a positive result (i.e. a score of at least 27 points), the study assistant informs the person about the trial. The study assistant hands out the study documents to the patient. An information letter details the content and objectives of the study as well as the patient's personal rights regarding the handling of personal data. In case of participation, the patients endorse informed consent and complete the baseline questionnaire. If one of the follow-up questionnaires is not returned, a questionnaire will be sent again, with a reminder to all participants after 3 weeks.

Recruitment for the interviews will be carried out by the study assistants in the rehabilitation centers. Informed consent forms are handed out during the 
Table 2 Schedule of enrolment, interventions and assessments

\begin{tabular}{|c|c|c|c|c|c|c|}
\hline Outcome & Source and reference & Scaling & Baseline & $\left|\begin{array}{l}\text { End of } \\
\text { rehabilitation }\end{array}\right|$ & $\begin{array}{l}\text { 3-Month } \\
\text { follow-up }\end{array}$ & $\begin{array}{l}\text { 12-Month } \\
\text { follow-up }\end{array}$ \\
\hline \multicolumn{7}{|l|}{ Primary outcome } \\
\hline Stable return to work & Own development & Binary & & & $\mathrm{X}$ & $\mathrm{X}$ \\
\hline \multicolumn{7}{|l|}{ Secondary outcomes } \\
\hline Employment & Own development & Binary & $\mathrm{X}$ & & $\mathrm{X}$ & $\mathrm{X}$ \\
\hline Current sickness absence & Own development & Binary & $\mathrm{X}$ & & $\mathrm{X}$ & $\mathrm{X}$ \\
\hline Sick leave duration in weeks & Own development & Metric & $\mathrm{X}$ & & $\mathrm{X}$ & $\mathrm{X}$ \\
\hline Subjective work ability & WAS [35] & Metric & $\mathrm{X}$ & & $\mathrm{X}$ & $\mathrm{X}$ \\
\hline Health-related quality of life & SF-36 [37] & Metric & $\mathrm{X}$ & $\mathrm{X}$ & $\mathrm{X}$ & $\mathrm{X}$ \\
\hline Psychosocial health & HEALTH-49 [38] & Metric & $\mathrm{X}$ & $\mathrm{X}$ & $\mathrm{X}$ & $\mathrm{X}$ \\
\hline Job-related anxieties & Workplace phobia scale $[39,40]$ & Metric & $\mathrm{X}$ & $\mathrm{X}$ & $\mathrm{X}$ & $\mathrm{X}$ \\
\hline Regeneration and resistance & $\operatorname{Re} \operatorname{Re}[41]$ & Metric & $\mathrm{X}$ & $\mathrm{X}$ & $\mathrm{X}$ & $\mathrm{X}$ \\
\hline Work-related content & [42] & Metric & & $\mathrm{X}$ & & \\
\hline Consistency of work-related strategy & [42] & Metric & & $\mathrm{X}$ & & \\
\hline Achievement of work-related goals & [42] & Metric & & $\mathrm{X}$ & & \\
\hline Treatment satisfaction & CSQ-8 [43] & Metric & & $\mathrm{X}$ & & \\
\hline \multicolumn{7}{|l|}{ Other measures } \\
\hline Therapeutic interventions & Rehabilitation discharge letters [44] & Metric & & $\mathrm{X}$ & & \\
\hline Socio-medical assessment of capacity & Rehabilitation discharge letters [44] & Nominal & & $\mathrm{X}$ & & \\
\hline Outcome & Source and reference & Scaling & Baseline & $\begin{array}{l}\text { End of } \\
\text { rehabilitation }\end{array}$ & $\begin{array}{l}\text { 3-Month } \\
\text { follow-up }\end{array}$ & $\begin{array}{l}\text { 12-Month } \\
\text { follow-up }\end{array}$ \\
\hline $\begin{array}{l}\text { Use of medical and non-medical health care } \\
\text { services }\end{array}$ & FIMA $[45,46]$ & Metric/nominal & $\mathrm{X}$ & & $\mathrm{X}$ & $\mathrm{X}$ \\
\hline Socio-demographic data & Own development & Metric/nominal & $\mathrm{X}$ & & & \\
\hline
\end{tabular}

recruitment process and can be discussed with the person carrying out the interview if necessary and will be signed before the first interview. However, the teams, team leaders and medical directorates will be recruited by the person conducting the interviews.

\section{Allocation}

A separate randomization sequence is created for each rehabilitation center by the University of Lübeck. For the computer-generated randomization lists, blocks of four and eight are combined in order to guarantee balanced case numbers, even if the lists cannot be processed completely. The randomization envelopes are sealed and will be opened in the rehabilitation centers after informed consent of the participants is determined. After arriving at one of the six study centers, the potential study participants are informed in detail about the study, both orally and in writing, and are asked to participate by the study assistants, who have been trained by the research team. In particular, the potential participants are informed that there will be two different study groups (intervention group and control group) and that allocation to the two groups will be randomized.

\section{Blinding}

No one will be blinded before, during or after the trial as the realized rehabilitation program will be recognizable for all stakeholders.

\section{Data collection}

Outcomes and other measures will be assessed with patient questionnaires or will be extracted from the rehabilitation discharge letters (see Table 2). For participants who do not complete follow-up questionnaires, missing data will be imputed. If participants withdraw their participation, the collected data will be deleted.

Three consecutive interviews with participants of the complementary panel study are planned. The first interviews will take place during rehabilitation in the rehabilitation centers as focus groups. After three and 12 months, follow-up interviews with the same sample will be conducted as individual interviews by telephone or video call. Furthermore, members of the multiprofessional teams, team leaders and the respective 


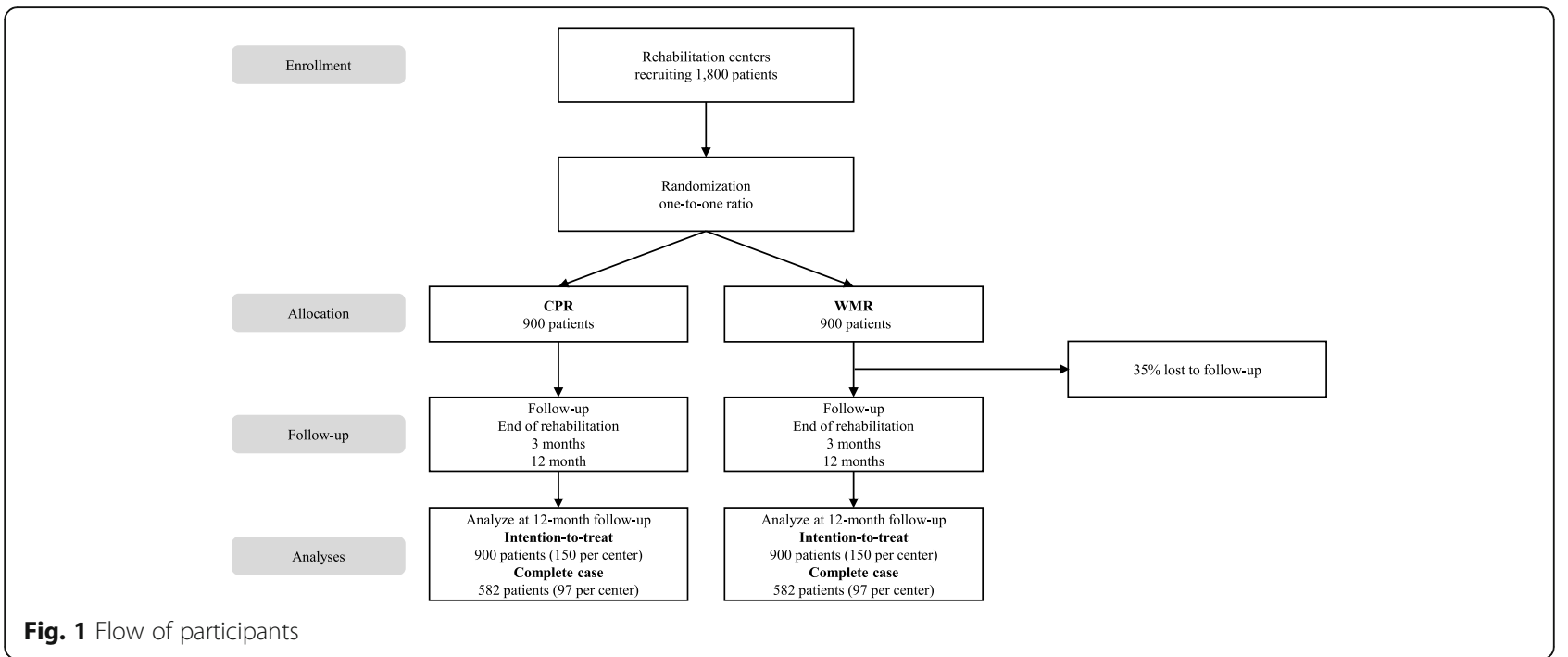

medical directorate of each rehabilitation center will be interviewed. Again, the first interviews will be conducted in the rehabilitation centers and the second interview after 6 months by telephone or video call. The interviews of teams and team leaders will be conducted as focus groups.

\section{Data management}

Questionnaires will be entered manually into an electronic database by trained research assistants at the University of Lübeck. Data on the documented therapeutic dose are taken from the rehabilitation discharge letters and will also be entered into the electronic database. All personal data will be removed and replaced by the unique study identifier by the rehabilitation centers.

Recordings from the focus groups and interviews will be transcribed by trained assistants at Nordhausen University of Applied Sciences. The names of patients and staff will be pseudonymized during the transcription process. These pseudonyms will be added to the study list. Finally, questionnaire, administrative and qualitative data can be linked by the unique study identifier. Data management will be carried out by the authors of the protocol. Data access is limited to the authors and to the research assistants in the research team.

\section{Statistical methods Treatment effect}

We use random-effects models to take into account that different true effects are possible in different rehabilitation centers. Linear models will be used for continuous outcomes and logistic models for binary outcomes. Baseline scores of outcomes will be included as covariates. Possible differences in effects at the level of the rehabilitation centers may be associated with WMR or CPR implementation. In order to test an effect modification due to the implementation of either WMR or CPR, subgroups are formed based on the received treatment dose (content, consistency, achievement of objectives) and the workrelated treatment dose delivered. To reduce the number of subgroup analyses, the mean differences between WMR and CPR for dose delivered and dose received are used to categorize the subgroups (high distinguishability vs. low distinguishability). We assume that greater distinguishability of both interventions based on treatment dose delivered and received is associated with higher effects. Further characteristics of the rehabilitation centers for subgroup analyses may derive from the focus groups. Gender, age, migration background and education are examined as possible moderating patient characteristics. Multiple imputations will be used to fill in missing data and to perform an intention-to-treat analysis.

\section{Health economic evaluation}

An incremental cost-utility analysis is performed [47]. Costs are recorded from the perspective of society as a whole [46]. For the evaluation of resources according to Seidl et al. [45], the calculated unit costs proposed by Bock et al. [46] are used. The recording of qualityadjusted life years for the evaluation of health benefits is conducted according to Brazier et al. [48].

\section{Focus groups and interviews}

Two central aspects will be examined in the qualitative part. On the one hand, we will identify personal and environmental facilitators and barriers [49], which influence a successful return to working life. On the other hand, the implementation of WMR as well as its further development and subsequent adaptions of the program's core components implementation process. This will be explored against the background of the implementation model "Consolidated Framework for Implementation Research" [50]. 
Table 3 Schedule of enrolment, interventions and assessments

\begin{tabular}{|c|c|c|c|c|c|c|c|c|}
\hline Timepoint & $\mid \begin{array}{l}\text { Pre- } \\
\text { intervention }\end{array}$ & $\begin{array}{l}\text { Randomi- } \\
\text { zation }\end{array}$ & \begin{tabular}{|l} 
Beginning of \\
intervention
\end{tabular} & $\begin{array}{l}\text { Third week of } \\
\text { intervention }\end{array}$ & $\begin{array}{l}\text { End of } \\
\text { intervention }\end{array}$ & $\begin{array}{l}\text { 3-Month } \\
\text { follow-up }\end{array}$ & $\begin{array}{l}\text { 6-Month } \\
\text { follow-up }\end{array}$ & $\begin{array}{l}\text { 12-Month } \\
\text { follow-up }\end{array}$ \\
\hline \multicolumn{9}{|l|}{ Enrolment } \\
\hline Information letter & $\mathrm{X}$ & & & & & & & \\
\hline Randomization & & $\mathrm{X}$ & & & & & & \\
\hline \multicolumn{9}{|l|}{ Interventions } \\
\hline Conventional psychosomatic rehabilitation & & & & & $\longrightarrow$ & & & \\
\hline Work-related medical rehabilitation & & & & & $\longrightarrow$ & & & \\
\hline \multicolumn{9}{|l|}{ Assessments } \\
\hline Patient baseline survey & $\mathrm{X}$ & & & & & & & \\
\hline Patient survey at the end of rehabilitation & & & & & $\mathrm{X}$ & & & \\
\hline Patient 3-month follow-up & & & & & & $\mathrm{X}$ & & \\
\hline Patient 12-month follow-up & & & & & & & & $\mathrm{X}$ \\
\hline Baseline focus group with patients & & & & $\mathrm{X}$ & & & & \\
\hline Baseline focus group with WMR teams & & & & $\mathrm{X}$ & & & & \\
\hline $\begin{array}{l}\text { Baseline focus group with WMR team } \\
\text { leaders }\end{array}$ & & & & $\mathrm{X}$ & & & & \\
\hline $\begin{array}{l}\text { Baseline focus group with medical } \\
\text { directorate }\end{array}$ & & & & $\mathrm{X}$ & & & & \\
\hline Patient 3-month follow-up interviews & & & & & & $\mathrm{X}$ & & \\
\hline Patient 12-month follow-up interviews & & & & & & & & $\mathrm{X}$ \\
\hline Team 6-month follow-up focus groups & & & & & & & $\mathrm{X}$ & \\
\hline $\begin{array}{l}\text { Team leader 6-month follow-up focus } \\
\text { groups }\end{array}$ & & & & & & & $\mathrm{X}$ & \\
\hline $\begin{array}{l}\text { Medical directorate 6-month follow-up } \\
\text { focus groups }\end{array}$ & & & & & & & $\mathrm{X}$ & \\
\hline
\end{tabular}

For these two interview areas, two research questions are guiding. First, which characteristics of the patient and which environmental factors influence a successful return to working life after psychosomatic WMR? Second, which characteristics influence a successful implementation and realization of WMR?

The study will be conducted as a qualitative longitudinal study. Data will be collected using guided interviews [51]. The interviews will be conducted by one of the authors (NG).

A maximum of eight patients (each intervention group and control group) from the six participating rehabilitation facilities will be interviewed three times. Patients already participating in the quantitative study will be eligible for participation. The first interview will be conducted in the clinics as a focus group. We will start with discussing personal and environmental factors, then we will address the implementation of WMR and its core components. The second and third interview will each be conducted by telephone or video conference 3 months and 12 months after the end of rehabilitation. We will include three patients from each focus group for these follow-up interviews. The guidelines of the followup interviews are similar to the initial guidelines, but their content is adapted to the home situation to be able to explore the individual course after rehabilitation.

In addition, one team per rehabilitation facility, all team leaders and the medical directors are interviewed. Two interviews are planned with these participants. The first appointment will be conducted in person in the rehabilitation facility. The second interview, 6 months later, will be held by telephone or video conference. All interviews with teams and team leaders are conducted as focus groups. The interviews of the teams, team leaders and medical directors broach the same broad two areas as those of the patients. However, the patients' situation will be assessed from a professional perspective. In addition, the working conditions of the therapeutic staff in the rehabilitation facilities will be addressed in these interviews.

The follow-up interviews are done to be able to capture changes and progress. A pretest is planned to clarify the feasibility and appropriateness of our interview questions. We will adapt our final guide accordingly. All 
interviews are transcribed [52] and analyzed by content analysis [53]. We will use quality criteria for quality research to outline the applicability of our findings [53].

\section{Monitoring}

A data and safety monitoring board accompanies the study. The committee consists of four statisticians and psychologists who attend the advisory board meetings, have insight into the statistical methods and provide advice to the university researchers. The committee provides feedback on the current status of the study and on already available results. The feedback is given orally at the advisory board meetings or in writing when milestones are reached. Members of the data and safety monitoring board are independent of the sponsor and have no competing interests.

The study assistants in the rehabilitation centers, who were recruited and trained specifically for the study, provide the universities with feedback on spontaneously reported adverse events and other unintended effects of trial interventions or trial conduct. The universities then document this information.

\section{Discussion}

This study is intended to provide evidence of the relative effectiveness of a complex, newly implemented work-related rehabilitation strategy for patients with mental disorders. We will provide a detailed description of the programs on our website: www.mbor-psychosomatik.de. The findings of this study will be published in peer-reviewed journal articles and conference presentations.

The study protocol has been prepared according to the SPIRIT checklist (Standard Protocol Items: Recommendations for Interventional Trials) [54].

\footnotetext{
Abbreviations

CPR: Conventional psychosomatic rehabilitation; FIMA: Questionnaire for Health-Related Resource Use in an Elderly Population (Fragebogen zur Inanspruchnahme medizinischer und nicht-medizinischer Versorgungsleistungen im Alter); GPI: German Pension Insurance; ReRe: Resistance and Regeneration Orientation Scale (Resistenzorientierung-Regenerationsorientierungs-Skala); SF-36: 36-Item Short-Form Health Survey; WAl: Work Ability Index; WAS: Work Ability Score; WMR: Work-related medical rehabilitation
}

\section{Supplementary Information}

The online version contains supplementary material available at https://doi. org/10.1186/s12888-021-03181-7.

Additional file 1. Participant information letter.

\section{Acknowledgments}

We thank Alexandra Lambrecht and the team of Rehazentrum Oberharz in Clausthal-Zellerfeld, Volker Köllner, Ulrich Adam-Keßler and the team of RehaZentrum Seehof in Teltow, Timo Specht, Frank Rosbiegal and the team of
Fachklinik Aukrug, Andrea Budde, Astrid Jeising and the team of Klinik am Hainberg in Bad Hersfeld, Barbara Guldin and the team of Celenus Parkklinik in Bad Bergzabern and Michael Käfer and the team of MediClin Bliestal Kliniken in Blieskastel for cooperating in our study.

\section{Authors' contributions}

MBE, MBA, MM and NG developed the study design. All authors contributed to drafting the manuscript. All authors finally read and approved the manuscript for submission. All authors fulfill the authorship criteria of the International Committee of Medical Journal Editors.

\section{Funding}

The study is funded by the Federal German Pension Insurance, Ruhrstr. 2, 10709 Berlin, Germany (grant number: 0421/00-40-69-10-11) through grant program "Forschung und Ergebnistransfer für eine bedarfsorientierte Rehabilitation" (Research and Transfer of Results for Needs-Based Rehabilitation), which was initiated by the Federal Ministry of Education and Research and the Federal German Pension Insurance to generate scientifically sound findings on needs-based rehabilitation in routine care and to transfer research findings into practice. Funding covers personnel, material and traveling expenses. The funding body has no impact on the design of the study, data collection, data analysis, data interpretation, and on writing the manuscript. Open Access funding enabled and organized by Projekt DEAL.

\section{Availability of data and materials}

Not applicable.

\section{Declarations}

\section{Ethics approval and consent to participate}

The investigation conforms to the principles outlined in the Declaration of Helsinki. The study protocol was approved by the ethics committee of the University of Lübeck (18-141) and participation in the study is voluntary. Written, informed consent to participate will be obtained from all participants (see Additional file 1).

The study has been registered in the German Clinical Trials Register (DRKS00023175).

This paper contains the original study protocol. Any substantial modifications to the study protocol will be notified to the ethics committee of the University of Lübeck for approval prior to implementation. These amendments will be documented in detail in the German Clinical Trials Register and will be described transparently in trial reports. After completion of the study, the study participants receive an information brochure with key results.

\section{Consent for publication}

Not applicable.

\section{Competing interests}

The authors declare that they have no competing interests.

\section{Author details}

${ }^{1}$ Institute of Social Medicine and Epidemiology, University of Lübeck, Ratzeburger Allee 160, 23562 Lübeck, Germany. ${ }^{2}$ Rehabilitation Sciences and Health Services Research, Institute for Social Medicine, Nordhausen University of Applied Sciences, Weinberghof 4, Nordhausen 99734, Germany.

Received: 11 February 2021 Accepted: 22 March 2021

Published online: 03 May 2021

\section{References}

1. Jacobi F, Hofler M, Strehle J, Mack S, Gerschler A, Scholl L, et al. Mental disorders in the general population: study on the health of adults in Germany and the additional module mental health (DEGS1-MH). Nervenarzt. 2014;85(1):77-87. https://doi.org/10.1007/s00115-013-3961-y.

2. Richter $D$, Berger $K$, Reker $T$. Are mental disorders on the increase? A systematic review. Psychiatr Prax. 2008;35(07):321-30. https://doi.org/10.1 055/s-2008-1067570.

3. Meyer M, Weirauch $H$, Weber F. Krankheitsbedingte Fehlzeiten in der deutschen Wirtschaft im Jahr 2014. In: Badura B, Ducki A, Schröder H, Klose 
J, Meyer M, editors. Fehlzeiten-Report 2015. Berlin: Springer; 2015. p. 341548. https://doi.org/10.1007/978-3-662-47264-4_30.

4. DAK. Gesundheitsreport 2016. Hamburg: DAK-Gesundheit; 2016.

5. Rehfeld UG. Gesundheitsbedingte Frühberentung. Berlin: Robert KochInstitut; 2006.

6. Bundesministerium für Arbeit und Soziales. Zweiter Teilhabebericht der Bundesregierung über die Lebenslagen von Menschen mit Beeinträchtigungen. Bonn: Bundesministerium für Arbeit und Soziales; 2016.

7. Kühn KU, Quednow BB, Barkow K, Heun R, Linden M, Maier W. Chronifizierung und psychosoziale Behinderung durch depressive Erkrankungen bei Patienten in der Allgemeinarztpraxis im Einjahresverlauf Ergebnisse aus einer Studie der Weltgesundheitsorganisation. Nervenarzt. 2002;73(7):644-50. https://doi.org/10.1007/s00115-002-1334-z.

8. Stucki G, Bickenbach J, Gutenbrunner C, Melvin J. Rehabilitation: the health strategy of the 21st century. J Rehabil Med. 2018;50(4):309-16. https://doi. org/10.2340/16501977-2200.

9. Deutsche Rentenversicherung Bund. Rentenversicherung in Zahlen 2016. Berlin: Deutsche Rentenversicherung Bund; 2016.

10. Deutsche Rentenversicherung Bund. Rehabilitation 2015. Statistik der Deutschen Rentenversicherung. Berlin: Deutsche Rentenversicherung Bund; 2016.

11. Hillert A, Staedtke D, Heldwein C, Toth A, Cuntz U. Randomisierte Evaluation der beruflichen Belastungserprobung (BE) bei psychosomatischen Patienten im Rahmen eines stationären verhaltenstherapeutischen Settings: 12Monatskatamnese. DRV-Schriften. 2003;40:287-90.

12. Beutel ME, Zwerenz R, Bleichner F, Vorndran A, Gustson D, Knickenberg RJ. Vocational training integrated into inpatient psychosomatic rehabilitation: short and long-term results from a controlled study. Disabil Rehabil. 2005; 27(15):891-900. https://doi.org/10.1080/09638280500030464.

13. Nieuwenhuijsen K, Faber B, Verbeek JH, Neumeyer-Gromen A, Hees HL, Verhoeven AC, et al. Interventions to improve return to work in depressed people. Cochrane Database Syst Rev. 2014;12:Cd006237.

14. Bethge M. Rehabilitation and work participation. Bundesgesundheitsbla. 2017:60(4):427-35. https://doi.org/10.1007/s00103-017-2519-8.

15. Streibelt M, Buschmann-Steinhage R. A profile of requirements for the performance of work related medical rehabilitation from the perspective of the statutory pension insurance. Rehabilitation. 2011;50(3):160-7. https://doi. org/10.1055/s-0031-1275721.

16. Bethge M. Work-related medical rehabilitation. Rehabilitation. 2017;56(1):14-21.

17. Bethge M, Löffler S, Schwarz B, Vogel H, Schwarze M, Neuderth S. Is the guideline for work-related medical rehabilitation successfully implemented? Rehabilitation. 2014;53(03):184-90.

18. Bethge M, Herbold D, Trowitzsch L, Jacobi C. Work status and health-related quality of life following multimodal work hardening: a cluster randomised trial. J Back Musculoskelet Rehabil. 2011;24(3):161-72. https://doi.org/1 0.3233/BMR-2011-0290.

19. Kleist B, Alliger K, Winter S, Beyer WF. Work Hardening bei chronischen unspezifischen Rückenschmerzen in der stationären Rehabilitation. Praxis Klin Verhaltensmed Rehab. 2001:14(54):145-50.

20. Streibelt $M$, Bethge M. Effects of intensified work-related multidisciplinary rehabilitation on occupational participation: a randomized-controlled trial in patients with chronic musculoskeletal disorders. Int J Rehabil Res. 2014;37(1): 61-6. https://doi.org/10.1097/MRR.0000000000000031.

21. Streibelt M, Bethge M, Gross T, Herrmann K, Ustaoglu F, Reichel C. Predictive validity of a screening instrument for the risk of non-return to work in patients with internal diseases. Arch Phys Med Rehabil. 2017; 98(5):989-96 e1.

22. Streibelt $M$, Bethge M. Prospective cohort analysis of the predictive validity of a screening instrument for severe restrictions of work ability in patients with musculoskeletal disorders. Am J Phys Med Rehabil. 2015;94(8):617-26. https://doi.org/10.1097/PHM.0000000000000220

23. Streibelt M. Validity and reliability of a screening instrument for the identification of extensive work-related problems in patients with chronic diseases (SIMBO-C). Rehabilitation. 2009;48(03):135-44. https://doi.org/10.1 055/s-0029-1220742

24. Streibelt M, Bethge M. Prognostic accuracy of the SIMBO regarding future return-to-work problems in patients with mental and musculoskeletal disorders. Disabil Rehabil. 2019;41(13):1571-7. https://doi.org/10.1080/0963 8288.2018.1432703.

25. Deutsche Rentenversicherung Bund. Anforderungsprofil für eine stationäre Einrichtung zur medizinischen Rehabilitation von Erwachsenen mit psychosomatischen und psychischen Störungen. Berlin: Deutsche Rentenversicherung Bund; 2010.

26. Deutsche Rentenversicherung Bund. Reha-Therapiestandards Depressive Störungen. Berlin: Deutsche Rentenversicherung Bund; 2016.

27. Deutsche Rentenversicherung Bund. Anforderungsprofil zur Durchführung der Medizinisch-beruflich orientierten Rehabilitation (MBOR) im Auftrag der Deutschen Rentenversicherung. 3rd ed. Berlin: Deutsche Rentenversicherung Bund; 2012.

28. Zoer I, de Graaf L, Kuijer PP, Prinzie P, Hoozemans MJ, Frings-Dresen MH. Matching work capacities and demands at job placement in employees with disabilities. Work. 2012;42(2):205-14. https://doi.org/10.3233/WOR-2 012-1343.

29. Toeppen-Sprigg B. Importance of job analysis with functional capacity matching in medical case management: a physician's perspective. Work. 2000:15(2):133-7.

30. Voss M, Schutte M, Wieland K. Synopsis of procedures used in the evaluation of the physically handicapped and work demands. Rehabilitation. 1988;27(3):135-9.

31. Mozdzanowski M, Glatz A. Das Profilvergleichssystem IMBA als Instrument im betrieblichen Eingliederungsmanagement. B\&G Bewegungsther Gesundheitssport. 2013;29(02):55-61. https://doi.org/10.1055/s-0032-1331 093.

32. Deutsche Rentenversicherung Bund. Klassifikation therapeutischer Leistungen in der medizinischen Rehabilitation. Berlin: Deutsche Rentenversicherung Bund; 2014.

33. Hoffmann TC, Glasziou PP, Boutron I, Milne R, Perera R, Moher D, et al. Better reporting of interventions: template for intervention description and replication (TIDieR) checklist and guide. BMJ. 2014;348:g1687. https://doi. org/10.1136/bmj.g1687.

34. Kuijer PP, Gouttebarge V, Wind H, van Duivenbooden C, Sluiter JK, FringsDresen MH. Prognostic value of self-reported work ability and performancebased lifting tests for sustainable return to work among construction workers. Scand J Work Environ Health. 2012;38(6):600-3. https://doi.org/10. 5271/sjweh.3302.

35. IImarinen J. The Work Ability Index (WAI). Occup Med (Lond). 2007;57(2):160

36. El Fassi M, Bocquet V, Majery N, Lair ML, Couffignal S, Mairiaux P. Work ability assessment in a worker population: comparison and determinants of work ability index and work ability score. BMC Public Health. 2013;13(1):305. https://doi.org/10.1186/1471-2458-13-305.

37. Morfeld M, Kirchberger I, Bullinger M. SF-36 Fragebogen zum Gesundheitszustand: Deutsche Version des Short Form-36 Health Survey. 2nd ed. Göttingen: Hogrefe; 2011.

38. Sven R, Timo H, Stephan K, Uwe K, Hans-Ulrich W, Holger S. Psychometrische Überprüfung einer verkürzten Version der Hamburger Module zur Erfassung allgemeiner Aspekte psychosozialer Gesundheit für die therapeutische Praxis (HEALTH-49). Z Psychosom Med Psychother. 2009; 55(2):162-79.

39. Muschalla B, Linden $M$, Jöbges $M$. Work-anxiety and sickness absence after a short inpatient cognitive behavioral group intervention in comparison to a recreational group meeting. J Occup Environ Med. 2016;58(4):398-406. https://doi.org/10.1097/JOM.0000000000000678.

40. Linden M, Muschalla B, Olbrich D. Die Job-Angst-Skala (JAS). Ein Fragebogen zur Erfassung arbeitsplatzbezogener Ängste. Z Arb Organ. 2008; 52:126-34.

41. Otto J, Linden M. Erfassung der Stressverarbeitungsstrategien Regenerations- und Resistenzorientierung. Z Psychiatr Psychol Psychother. 2017:65(4):231-9. https://doi.org/10.1024/1661-4747/a000326.

42. Bethge M, Markus M, Streibelt M, Gerlich C, Schuler M. Effects of nationwide implementation of work-related medical rehabilitation in Germany: propensity score matched analysis. Occup Environ Med. 2019;76(12):913-9. https://doi.org/10.1136/oemed-2019-106065.

43. Attkisson CC, Zwick R. The client satisfaction questionnaire. Psychometric properties and correlations with service utilization and psychotherapy outcome. Eval Program Plann. 1982;5(3):233-7. https://doi.org/10.1016/01497189(82)90074-X.

44. Deutsche Rentenversicherung Bund. Der ärztliche Reha-Entlassungsbericht Leitfaden zum einheitlichen Entlassungsbericht in der medizinischen Rehabilitation der gesetzlichen Rentenversicherung 2015. Berlin: Deutsche Rentenversicherung Bund; 2020.

45. Seidl H, Bowles D, Bock JO, Brettschneider C, Greiner W, König HH, et al. FIMA - questionnaire for health-related resource use in an elderly 
population: development and pilot study. Gesundheitswesen. 2015;77(1):4652. https://doi.org/10.1055/s-0034-1372618.

46. Bock JO, Brettschneider C, Seidl H, Bowles D, Holle R, Greiner W, et al. Calculation of standardised unit costs from a societal perspective for health economic evaluation. Gesundheitswesen. 2015;77(01):53-61.

47. Glick HA, Doshi JA, Sonnad SS, Polsky D. Economic evaluation in clinical trials. Oxford: Oxford University Press; 2015.

48. Brazier J, Roberts J, Deverill M. The estimation of a preference-based measure of health from the SF-36. J Health Econ. 2002;21(2):271-92. https:// doi.org/10.1016/S0167-6296(01)00130-8.

49. World Health Organization. International classification of functioning, disability and health: ICF. Geneva: World Health Organization; 2001.

50. Damschroder L, Aron DC, Keith RE, Kirsh SR, Alexander JA, Lowery JC. Fostering implementation of health services research findings into practice: a consolidated framework for advancing implementation science. Implement Sci. 2009;4(1):50. https://doi.org/10.1186/1748-5908-4-50

51. Gläser J, Laudel G. Experteninterviews und qualitative Inhaltsanalyse als Instrumente rekonstruierender Untersuchungen. 4th ed. Wiesbaden: Verlag für Sozialwissenschaften; 2010. https://doi.org/10.1007/978-3-531-91538-8.

52. Kuckartz U. Einführung in die computergestützte Analyse qualitativer Daten. Wiesbaden: Verlag für Sozialwissenschaften; 2005. https://doi.org/10.1007/ 978-3-322-93531-1.

53. Mayring P. Qualitative Inhaltsanalyse. Grundlagen und Techniken. Weinheim: Beltz Verlagsgruppe; 2015.

54. Chan AW, Tetzlaff JM, Gotzsche PC, Altman DG, Mann H, Berlin JA, Dickersin K, Hrobjartsson A, Schulz KF, Parulekar WR, Krleza-Jeric K, Laupacis A, Moher D SPIRIT 2013 explanation and elaboration: guidance for protocols of clinical trials. BMJ 2013;346:e7586, DOI: https://doi.org/10.1136/bmj.e7586.

\section{Publisher's Note}

Springer Nature remains neutral with regard to jurisdictional claims in published maps and institutional affiliations.

Ready to submit your research? Choose BMC and benefit from:

- fast, convenient online submission

- thorough peer review by experienced researchers in your field

- rapid publication on acceptance

- support for research data, including large and complex data types

- gold Open Access which fosters wider collaboration and increased citations

- maximum visibility for your research: over $100 \mathrm{M}$ website views per year

At $\mathrm{BMC}$, research is always in progress.

Learn more biomedcentral.com/submissions 